\title{
A Group Increment Scheme for Infrared Absorption Intensities of Greenhouse Gases
}

Sara I. Kokkila ${ }^{1}$, Partha P. Bera ${ }^{2}$, Joseph S. Francisco ${ }^{3}$, Timothy J. Lee ${ }^{4 *}$

1. College of Saint Benedict and Saint John's University, Saint Joseph, MN, 56374

2. NASA Ames Research Center, Mountain View, CA, 94035

3. Department of Chemistry and Department of Earth and Atmospheric Sciences, Purdue University, West Lafayette, IN, 47907

4. NASA Ames Research Center, Mountain View, CA, 94035

E-mail: Timothy.J.Lee@nasa.gov, Corresponding author. 


\begin{abstract}
A molecule's absorption in the atmospheric infrared (IR) window (IRW) is an indicator of its efficiency as a greenhouse gas. A model for estimating the absorption of a fluorinated molecule within the IRW was developed to assess its radiative impact. This model will be useful in comparing different hydrofluorocarbons and hydrofluoroethers contribution to global warming. The absorption of radiation by greenhouse gases, in particular hydrofluoroethers and hydrofluorocarbons, was investigated using ab initio quantum mechanical methods. Least squares regression techniques were used to create a model based on this data. The placement and number of fluorines in the molecule were found to affect the absorption in the IR window and were incorporated into the model. Several group increment models are discussed. An additive model based on one-carbon groups is found to work satisfactorily in predicting the ab initio calculated vibrational intensities.
\end{abstract}




\section{Introduction}

Greenhouse gases (GHGs), such as chlorofluorocarbons (CFCs), perfluorocarbons (PFCs), and hydrofluorocarbons (HFCs) can contribute significantly to climate change. ${ }^{1}$ Since the Montreal Protocol and the initial IPCC assessment, the Environmental Protection Agency (EPA) has investigated the use of HFCs and hydrofluoroethers (HFEs) as possible replacements for CFCs. ${ }^{2}$ Although the industrial use of CFCs have been phased out, PFCs and HFCs are currently used heavily in the air conditioning, carpeting, drug, and the electronics industries. ${ }^{3,4}$ In addition, they are used as tracers in atmospheric studies and have some medical applications. ${ }^{5,6}$ These greenhouse gases (HFCs, PFCs), which possess carbon-fluorine bonds, are known to absorb heavily in the atmospheric infrared (IR) window. The relative climate impact of these gases, as expressed by the global warming potential (GWP), is sometimes thousands of times that of $\mathrm{CO}_{2}$ due to their inherent ability to absorb radiation within the Earth's atmospheric IR window (IRW). The GWP is defined as the ratio of the time-integrated radiative forcing from the instantaneous release of one kilogram of a trace substance relative to that of one kilogram of a reference gas, which is usually taken to be $\mathrm{CO}_{2} \cdot{ }^{1,7}$ The radiative forcing of a molecule has been shown to depend on its radiative efficiency and atmospheric abundance. ${ }^{7}$ A large molecular radiative efficiency has been shown by Bera et al. to arise when a molecule exhibits a large infrared absorption intensity within the IR window due to large dipole derivatives of highly polar bonds. ${ }^{8}$ Moreover, HFCs and especially PFCs, tend to possess long atmospheric lifetimes since carbon-fluorine bonds are generally not very reactive with hydroxyl radicals in the atmosphere. All of these factors lead to a large global warming potential. Finally, based on the analysis of the molecular origin of the strong absorption of radiation within the atmospheric IR window, ${ }^{8}$ design strategies were devised to minimize an industrial molecule's radiative efficiency. ${ }^{9}$ 
Due to the relatively shorter atmospheric lifetimes, HFEs have been recommended as alternatives for PFCs and HFCs. ${ }^{10,11}$ HFEs generally have an increased reactivity with hydroxyl radicals, which decreases their atmospheric lifetimes. ${ }^{12}$ However, they absorb IR radiation very efficiently in the Earth's atmospheric window wavelength range. ${ }^{9,13}$ The carbon-oxygen stretches fall within the atmospheric IRW and have a large IR intensity due to the polarity of the $\mathrm{C}-\mathrm{O}$ bond. This in combination with the carbon-fluorine vibrational stretch, which also occurs within the atmospheric IRW, makes perfluoroethers (PFEs) and HFEs very effective greenhouse gases. ${ }^{8,9,12,14-18}$

For fluorinated hydrocarbons and ethers, molecular structure greatly impacts its ability to absorb IR radiation. ${ }^{9}$ It has been shown that by strategic distribution of fluorine atoms along the carbon framework, the infrared radiation absorption capacity can be reduced by a factor of two. ${ }^{8,9}$ Based on this knowledge, a group increment scheme for absorption intensities is proposed and investigated in the present study. The idea of a group increment scheme is analogous to Benson's work with molecular thermodynamic properties. Benson approached the idea of describing thermodynamic properties by distinguishing different groups within a molecule and applying additivity rules. ${ }^{19}$ With the different groups and their corresponding thermodynamic quantities, one can simply add the values of the different groups within a given molecule and estimate one of several thermodynamic properties. In a similar manner, PFCs, HFCs, PFEs, and HFEs can be characterized by different groups present in them, such as $\mathrm{CF}_{3}, \mathrm{CF}_{2}, \mathrm{CHF}_{2}, \mathrm{CH}_{2} \mathrm{~F}$, $\mathrm{CH}_{2}$, CHF-O etc, in order to estimate the integrated infrared absorption intensity for a given molecule. Each group has a 'base value', which is determined by a specific model. Each groups' effective contribution, i.e. 'base value' towards the total infrared absorption, is then estimated using a regression analysis of infrared intensities on a test set of over 350 fluorocarbons that 
included hydrofluorocarbons, perfluorocarbons, hydrofluoroethers and perfluoroethers in this work. Due to the nature of groups present in the partially or fully fluorinated hydrocarbons as opposed to partially and fully fluorinated ethers, two sets of base values are estimated for similar groups, or in other words, we develop a model for fluorocarbons and a separate model for fluoroethers. These 'base values' are expected to greatly simplify the process of estimating infrared absorption intensities and thus molecular radiative efficiencies for PFCs, HFCs, PFEs, and HFEs. Also, while the exact definition of the Earth's IR window has varied from one work to another, for purposes of the present study we define the window as $775 \mathrm{~cm}^{-1}$ to $1425 \mathrm{~cm}^{-1}$ in order to be inclusive. We realize that this is a relatively large defined IRW, but we note that the vibrational frequencies we use are harmonic, and inclusion of anharmonic contributions would lower the stretching modes, in particular, by $15-30 \mathrm{~cm}^{-1}$.

Before proceeding, we point out that there has been some discussion in the literature recently concerning a molecule's radiative efficiency (RE) versus its integrated IR absorption intensity within the Earth's IRW. ${ }^{20,21}$ Firstly, we note that the term RE has been used inconsistently in the literature, and in some cases RE is used in a fashion in which it is essentially the integrated IR intensity. However, the most commonly used definition for RE is related to the molecule's integrated IR intensity, but also is multiplied by the Planck function (usually using a narrow band model - see Refs. 22 and 23) 22,23 , and can also take into account IR absorption by other molecules in the atmosphere. Essentially, the RE defined in this way is part of the radiative transfer model used as part of a climate model. One concern, however, that we have with this approach is that it does not take into account the number of photons that can be processed per second by a single molecule (i.e., the model lacks details from molecular physics). In any case, we plan to explore this further in the future, but this is beyond the scope of the present study. 
Hence for the present investigation we limit the group increment scheme to the integrated IR intensity within the IRW, knowing full well that one could adapt this method for REs (computed using the narrow band model Planck function, etc.) and expect similar results.

In the next two sections the methods for obtaining the 'base values' for the groups and their use in obtaining total absorption intensities are explained.

\section{Theoretical Methods}

The molecular geometries were optimized using the second-order Møller-Plesset perturbation theory (MP2) along with a double zeta plus polarization one-particle basis set, denoted DZP++, which includes diffuse functions on hydrogen atoms as well as the heavy atoms. ${ }^{24-26}$ The MP2 method was chosen rather than a density functional theory (DFT) approach, for example B3LYP, because while the B3LYP method may fortuitously yield harmonic frequencies that are closer to the experimental fundamental vibrational frequency compared to MP2, it is our experience that MP2 is superior in predicting the IR intensities. ${ }^{27,28}$ This is explained by the well known fact that DFT methods generally do not describe the diffuse part of wave functions reliably, and electrical properties such as the dipole moment, dipole derivatives, polarizabilities, etc. all depend significantly on the diffuse part of the wave function. All $a b$ initio electronic structure calculations were performed using the Q-Chem3.1 quantum chemistry program. ${ }^{29}$ Harmonic vibrational frequencies and IR intensities were computed at the same level of theory (MP2/DZP++). The IR intensities were computed under the double harmonic approximation, meaning the harmonic oscillator approximation was utilized in the mechanical and electrical framework. With this approximation, the IR vibrational intensities are proportional to the square

of the dipole derivatives. ${ }^{30}$ From comparison with experimental data, the IR intensities computed 
at the MP2/DZP++ level of theory are expected to be between 5-20\% larger than experimental values. ${ }^{31}$ For determining whether this type of model can work for IR intensities, the MP2/DZP++ level of theory is adequate. Linear least squares regression models were determined using Minitab 15 Statistical Software (2007). ${ }^{32} \mathrm{R}^{2}$ values, residuals, and fitted intensity values were computed using Minitab 15.

\section{Statistical Background}

The residual is defined as the difference between the intensity calculated by ab initio methods and the intensity predicted by the model,

$$
e_{i}=y_{i}-\hat{y}_{i}
$$

The fitted intensities matrix that minimizes the sum of squares is given by the following formula where $\mathrm{X}$ represents the matrix that has $\mathrm{n}$ molecules as rows and $\mathrm{m}$ columns of $\mathrm{x}$-variables. $\hat{\beta}$ denotes the matrix consisting of the fitted parameters, and y represents the column matrix consisting of all ab initio calculated intensities.

$$
\begin{aligned}
& \hat{\beta}=\left(X^{T} X\right)^{-1} X^{T} y \\
& \hat{y}=X \hat{\beta}=X\left(X^{T} X\right)^{-1} X^{T} y
\end{aligned}
$$

The coefficient of determination for a model with $n$ molecules is used to assess the fit of the model. It is given in Eq. 4 below where $\bar{y}$ represents the mean of the ab initio calculated intensities.

$$
R^{2}=1-\frac{\sum_{i=1}^{n} e_{i}^{2}}{\sum_{i=1}^{n}\left(y_{i}-\bar{y}\right)^{2}}
$$

$e \quad=$ residual 
$y=$ ab initio calculated IR absorption intensity

$\hat{y} \quad=$ IR absorption intensity predicted by model

$X \quad=$ matrix consisting of all input data for molecules

$\hat{\beta} \quad=$ matrix consisting of least squares fitted parameters

$R^{2} \quad=$ coefficient of determination

A summary of the linear regression analysis that we have used is contained in Ref. $33 .{ }^{33}$

\section{Results and Discussions}

\section{B. Hydrofluorocarbon and Perfluorocarbon Models}

We have used $a b$ initio quantum chemical methods to calculate the harmonic vibrational frequencies and intensities for IR absorption for partially and fully fluorinated two carbon, three carbon, four carbon molecules and partially fluorinated five-carbon molecules. For the two, three, and four carbon molecules, we started with singly fluorinated species and included all possible arrangements through molecules saturated with fluorine. From the ab initio computed intensities several model hydrocarbon and perfluorocarbons, shown in Table 1, were created.

The hydrofluorocarbon and perfluorocarbon molecules are broken down into one-carbon groups. In the simplest models we assume that the base values for one-carbon groups are independent of their neighboring groups. The first two additive models for predicting the molecule's absorption within the atmospheric IRW are based on this approximation and so do not include interaction terms between groups. Model 1 also includes an intercept term to account for any residual absorption within the atmospheric IRW, which is not accounted for by the group base values. When this regression was run, the $\mathrm{CH}_{3}$ group was automatically removed from the regression due to high correlation. A group is considered highly correlated with other predictor 
variables if the regression of that variable on the other predictor variables results in a regression equation where $1-\mathrm{R}^{2}$ is less than $10^{-18}$. In Model 2, no intercept term is allowed to enter and the integrated intensity is represented by the sum of base values of the constituent one-carbon groups. When Model 2 was run, the $\mathrm{CH}_{3}$ group was no longer highly correlated with the other columns in the basis matrix and so was included in the final model. In a previous study by Bera et al., it was shown that increasing the number of carbon-fluorine bonds leads to a nonlinear increase in IR intensity. ${ }^{8}$ Since the carbon-hydrogen bond is less polar than the carbon-fluorine bond, the $\mathrm{CH}_{3}$ group may have been highly correlated with other predictor variables because the contributions from the carbon-fluorine bonds overwhelm the contributions from a group that consists of only carbon-hydrogen bonds. However, the $\mathrm{CH}_{2}$ group was not highly correlated with other predictor variables and was still included in the regression equation. Although it is included, the base values for the $\mathrm{CH}_{2}$ group is much smaller than the base values for groups containing at least one carbon-fluorine bond. For both Model 1 and Model 2, each group is defined by the combination of atoms attached to a carbon. For example, the molecule $\mathrm{CFH}_{2} \mathrm{CF}_{2} \mathrm{CFHCH}_{3}$ contains one $\mathrm{CFH}_{2}$ group, one $\mathrm{CF}_{2}$ group, one $\mathrm{CFH}$ group, and one $\mathrm{CH}_{3}$ group. The intensity in the IRW for this molecule was calculated by ab initio methods to be $536.2 \mathrm{~km} \mathrm{~mol}^{-1}$; Models 1 and 2 are used in the following manner to predict this intensity:

\section{Model 1}

Intensity in IRW $=86.6+704 \mathrm{CF}_{3}+303 \mathrm{CF}_{2} \mathrm{H}+77.2 \mathrm{CFH}_{2}+289 \mathrm{CF}_{2}+75.6 \mathrm{CFH}+14.8 \mathrm{CH}_{2}$

$$
\begin{aligned}
& =86.6+704(0)+303(0)+77.2(1)+289(1)+75.6(1)+14.8(0) \\
& =528.4 \mathrm{~km} \mathrm{~mol}^{-1}
\end{aligned}
$$

\section{Model 2}


Intensity in IRW $=748 \mathrm{CF}_{3}+346 \mathrm{CF}_{2} \mathrm{H}+121 \mathrm{CFH}_{2}+43.3 \mathrm{CH}_{3}+289 \mathrm{CF}_{2}+75.6 \mathrm{CFH}+14.8$

$\mathrm{CH}_{2}$

$$
\begin{aligned}
& =748(0)+346(0)+121(1)+43.3(1)+289(1)+75.6(1)+14.8(0) \\
& =528.9 \mathrm{~km} \mathrm{~mol}^{-1}
\end{aligned}
$$

Both Model 1 and 2 are in agreement with each other and predict the intensity in the atmospheric IRW well. In Model 1 and 2, the intensity in the IRW was under-predicted for the molecule $\mathrm{CF}_{3} \mathrm{CH}_{2} \mathrm{CH}_{2} \mathrm{CF}_{3}$. The histograms, Figure 1 and 2, of residuals for Models 1 and 2 are almost symmetric and bell-shaped, and show evidence of an outlier. For certain molecules that contain the same groups, Models 1 and 2 may predict the same intensities in IRW for different molecules. For example, with these models the molecules $\mathrm{CF}_{3} \mathrm{CFHCH}_{2} \mathrm{CH}_{3}$ and $\mathrm{CF}_{3} \mathrm{CH}_{2} \mathrm{CFHCH}_{3}$ would have the same predicted intensities.

Models 3 and 4, included in the supporting information available through the website, are used in a similar way to Models 1 and 2. However, these two models contain terms that account for all possible interactions of groups within the molecule. In other words every one-carbon group feels the presence of all the other groups in the molecules. In Model 3, the $\mathrm{CH}_{3}$ group and all $\mathrm{CH}_{3}$ interaction terms were highly correlated with other predictor variables and were not included in the final model. In Model 4, without the constant term, all interaction terms involving $\mathrm{CH}_{3}$ were highly correlated with other predictor variables and were automatically removed from the regression. Models 3 and 4 predict the same intensities in the IRW for a molecule. The interaction terms between the one-carbon groups are much smaller in magnitude than the onecarbon group values, and further, interaction terms for groups separated by one carbon or more are even smaller. The histograms (included in the supporting material) of residuals for these models are slightly skewed left, but the highest abundance of residuals is near zero. In certain 
cases, these models will predict the same intensities in IRW for different molecules. For instance, the molecules $\mathrm{CF}_{3} \mathrm{CF}_{2} \mathrm{CH}_{2} \mathrm{CH}_{3}$ and $\mathrm{CF}_{3} \mathrm{CH}_{2} \mathrm{CF}_{2} \mathrm{CH}_{3}$ would be predicted to have the same intensities in IRW when in reality their intensities differ. These models are used in the following way for the molecule $\mathrm{CF}_{3} \mathrm{CH}_{2} \mathrm{CH}_{2} \mathrm{CF}_{2} \mathrm{H}$ to predict the intensity of absorption within the IRW. This molecule has one $\mathrm{CF}_{3}$ group, two $\mathrm{CH}_{2}$ groups, one $\mathrm{CF}_{2} \mathrm{H}$ group, two $\mathrm{CF}_{3} / \mathrm{CH}_{2}$ interactions, two $\mathrm{CF}_{2} \mathrm{H} / \mathrm{CH}_{2}$ interactions, one $\mathrm{CF}_{3} / \mathrm{CF}_{2} \mathrm{H}$ interaction, and one $\mathrm{CH}_{2} / \mathrm{CH}_{2}$ interaction.

\section{Model 3}

Intensity in IRW $=99.5+680 \mathrm{CF}_{3}+307 \mathrm{CF}_{2} \mathrm{H}+85.0 \mathrm{CFH}_{2}+324 \mathrm{CF}_{2}+63.2 \mathrm{CFH}$

$$
\begin{aligned}
&-75.5 \mathrm{CH}_{2}-12.9 \mathrm{CF}_{3} / \mathrm{CF}_{2}+4.57 \mathrm{CF}_{3} / \mathrm{CFH}+60.0 \mathrm{CF}_{3} / \mathrm{CH}_{2} \\
&+ 22.5 \mathrm{CF}_{3} / \mathrm{CF}_{3}+3.9 \mathrm{CF}_{3} / \mathrm{CF}_{2} \mathrm{H}-3.4 \mathrm{CF}_{3} / \mathrm{CFH}_{2}-20.7 \mathrm{CF}_{2} \mathrm{H} / \mathrm{CF}_{2} \\
&- 14.9 \mathrm{CF}_{2} \mathrm{H} / \mathrm{CFH}+28.3 \mathrm{CF}_{2} \mathrm{H} / \mathrm{CH}_{2}+24.1 \mathrm{CF}_{2} \mathrm{H} / \mathrm{CF}_{2} \mathrm{H} \\
&+ 2.3 \mathrm{CF}_{2} \mathrm{H} / \mathrm{CFH}_{2}-19.9 \mathrm{CFH}_{2} / \mathrm{CF}_{2}-2.67 \mathrm{CFH}_{2} / \mathrm{CFH} \\
&+ 22.8 \mathrm{CFH}_{2} / \mathrm{CH}_{2}-6.9 \mathrm{CFH}_{2} / \mathrm{CFH}_{2}-42.7 \mathrm{CF}_{2} / \mathrm{CF}_{2}-9.5 \mathrm{CF}_{2} / \mathrm{CFH}+31.9 \mathrm{CF}_{2} / \\
& \mathrm{CH}_{2}+22.2 \mathrm{CFH} / \mathrm{CFH}+42.6 \mathrm{CFH} / \mathrm{CH}_{2}+33.4 \mathrm{CH}_{2} / \mathrm{CH}_{2} \\
&=99.5+680(1)+307(1)+85.0(0)+324(0)+63.2(0) \\
&-75.5(2)-12.9(0)+4.57(0)+60.0(2) \\
&+22.5(0)+3.9(1)-3.4(0)-20.7(0) \\
&-14.9(0)+28.3(2)+24.1(0) \\
&+2.3(0)-19.9(0)-2.67(0) \\
&+22.8(0)-6.9(0)-42.7(0)-9.5(0)+31.9(0)+22.2(0)+42.6(0)+33.4(1) \\
&=\quad 1149.4 \mathrm{~km} \mathrm{~mol}{ }^{-1}
\end{aligned}
$$




\section{Model 4}

$$
\begin{aligned}
\text { Intensity in IRW } & =730 \mathrm{CF}_{3}+356 \mathrm{CF}_{2} \mathrm{H}+135 \mathrm{CFH}_{2}+49.7 \mathrm{CH}_{3}+324 \mathrm{CF}_{2}+63.2 \mathrm{CFH} \\
& -75.5 \mathrm{CH}_{2}-12.9 \mathrm{CF}_{3} / \mathrm{CF}_{2}+4.57 \mathrm{CF}_{3} / \mathrm{CFH}+60.0 \mathrm{CF}_{3} / \mathrm{CH}_{2} \\
& +22.5 \mathrm{CF}_{3} / \mathrm{CF}_{3}+3.9 \mathrm{CF}_{3} / \mathrm{CF}_{2} \mathrm{H}-3.4 \mathrm{CF}_{3} / \mathrm{CFH}_{2}-20.7 \mathrm{CF}_{2} \mathrm{H} / \mathrm{CF}_{2} \\
& -14.9 \mathrm{CF}_{2} \mathrm{H} / \mathrm{CFH}+28.3 \mathrm{CF}_{2} \mathrm{H} / \mathrm{CH}_{2}+24.1 \mathrm{CF}_{2} \mathrm{H} / \mathrm{CF}_{2} \mathrm{H} \\
& +2.3 \mathrm{CF}_{2} \mathrm{H} / \mathrm{CFH}_{2}-19.9 \mathrm{CFH}_{2} / \mathrm{CF}_{2}-2.67 \mathrm{CFH}_{2} / \mathrm{CFH} \\
& +22.8 \mathrm{CFH}_{2} / \mathrm{CH}_{2}-6.9 \mathrm{CFH}_{2} / \mathrm{CFH}_{2}-42.7 \mathrm{CF}_{2} / \mathrm{CF}_{2}-9.5 \mathrm{CF}_{2} / \mathrm{CFH} \\
& +31.9 \mathrm{CF}_{2} / \mathrm{CH}_{2}+22.2 \mathrm{CFH} / \mathrm{CFH}+42.6 \mathrm{CFH}_{2} \mathrm{CH}_{2}+33.4 \mathrm{CH}_{2} / \mathrm{CH}_{2} \\
& \\
= & 730(1)+356(1)+135(0)+49.7(0)+324(0)+63.2(0) \\
& -75.5(2)-12.9(0)+4.57(0)+60.0(2) \\
& +22.5(0)+3.9(1)-3.4(0)-20.7(0) \\
& -14.9(0)+28.3(2)+24.1(0) \\
& +2.3(0)-19.9(0)-2.67(0) \\
& +22.8(0)-6.9(0)-42.7(0)-9.5(0) \\
& 1148.9 \mathrm{~km} \mathrm{~mol}^{-1}
\end{aligned}
$$

Notice that in both of these models there are negative base values for some group interaction terms. This is due to the effects of multicollinearity, meaning that some of the predictor variables are highly correlated with the other predictor variables. For the $\mathrm{CH}_{2}$ group, this does not mean that incorporating this group into the design of a molecule will decrease the absorption intensity in the IRW; it means some groups have a negative sign to balance the effects of high correlations 
between predictor variables. Presence of the negative coefficients in these two models is undesirable. Inclusion of the interaction terms between the one-carbon groups has little effect on the usefulness of the models.

Finally, since the interactions between groups that are separated by at least one carbon are weaker than the nearest neighbor interactions, Models 5 and 6 account for only the groups within the molecule and the nearest neighbor interactions. Model 5 has a constant term while Model 6 does not. Both the models predict the same values for some molecules and are presented in SI. With these models, the molecule $\mathrm{CF}_{2} \mathrm{HCFHCH}_{3}$ (which contains one $\mathrm{CF}_{2} \mathrm{H}$ group, one $\mathrm{CFH}$ group, one $\mathrm{CH}_{3}$ group, one $\mathrm{CF}_{2} \mathrm{H} / \mathrm{CFH}$ interaction, and one $\mathrm{CH}_{3} / \mathrm{CFH}$ interaction and by ab initio methods has an intensity in the IRW of $492.9 \mathrm{~km} \mathrm{~mol}^{-1}$ ) would be entered in the following way:

\section{Model 5}

Intensity in IRW $=-14.9+760 \mathrm{CF}_{3}+345 \mathrm{CF}_{2} \mathrm{H}+112 \mathrm{CFH}_{2}+318 \mathrm{CF}_{2}+112 \mathrm{CFH}$

$$
\begin{aligned}
& +24.0 \mathrm{CH}_{2}-15.4 \mathrm{CF}_{3} / \mathrm{CF}_{2}-42.9 \mathrm{CF}_{3} / \mathrm{CFH}+2.4 \mathrm{CF}_{2} \mathrm{H} / \mathrm{CF}_{2} \\
& -25.6 \mathrm{CF}_{2} \mathrm{H} / \mathrm{CFH}+1.6 \mathrm{CFH}_{2} / \mathrm{CF}_{2}-0.8 \mathrm{CFH}_{2} / \mathrm{CFH}+58.1 \mathrm{CH}_{3} / \mathrm{CF}_{2} \\
& +29.3 \mathrm{CH}_{3} / \mathrm{CFH}-61.5 \mathrm{CF}_{2} / \mathrm{CF}_{2}-38.4 \mathrm{CF}_{2} / \mathrm{CFH}-14.9 \mathrm{CFH} / \mathrm{CFH}
\end{aligned}
$$

$$
\begin{aligned}
& =-14.9+760(0)+345(1)+112(0)+318(0)+112(1) \\
& +24.0(0)-15.4(0)-42.9(0)+2.4(0) \\
& -25.6(1)+1.6(0)-0.8(0)+58.1(0) \\
& +29.3(1)-61.5(0)-38.4(0)-14.9(0) \\
& =445.8 \mathrm{~km} \mathrm{~mol}^{-1}
\end{aligned}
$$

\section{Model 6}




$$
\begin{aligned}
\text { Intensity in IRW } & =752 \mathrm{CF}_{3}+338 \mathrm{CF}_{2} \mathrm{H}+104 \mathrm{CFH}_{2}-7.5 \mathrm{CH}_{3}+318 \mathrm{CF}_{2}+112 \mathrm{CFH} \\
& +24.0 \mathrm{CH}_{2}-15.4 \mathrm{CF}_{3} / \mathrm{CF}_{2}-42.9 \mathrm{CF}_{3} / \mathrm{CFH}+2.4 \mathrm{CF}_{2} \mathrm{H}_{2} \mathrm{CF}_{2} \\
& -25.6 \mathrm{CF}_{2} \mathrm{H} / \mathrm{CFH}+1.6 \mathrm{CFH}_{2} / \mathrm{CF}_{2}-0.8 \mathrm{CFH}_{2} / \mathrm{CFH}+58.1 \mathrm{CH}_{3} / \mathrm{CF}_{2} \\
& +29.3 \mathrm{CH}_{3} / \mathrm{CFH}-61.5 \mathrm{CF}_{2} / \mathrm{CF}_{2}-38.4 \mathrm{CF}_{2} / \mathrm{CFH}-14.9 \mathrm{CFH} / \mathrm{CFH} \\
= & 752(0)+338(1)+104(0)-7.5(1)+318(0)+112(1) \\
& +24.0(0)-15.4(0)-42.9(0)+2.4(0) \\
& -25.6(1)+1.6(0)-0.8(0)+58.1(0) \\
& +29.3(1)-61.5(0)-38.4(0)-14.9(0) \\
= & 446.2 \mathrm{~km} \mathrm{~mol}^{-1}
\end{aligned}
$$

Both models under predict the intensity in the IRW for the molecule $\mathrm{CF}_{3} \mathrm{CH}_{2} \mathrm{CH}_{2} \mathrm{CF}_{3}$. Disregarding outliers, the histograms (included in the supporting information) for these models are symmetric and bell-shaped curves centered on zero. These models also have some negative coefficients, which are once again due to the effects of multicollinearity. Despite being more sophisticated than the Models 1 and 2, these two models improve the prediction only marginally. Additionally the presence of the negative base values for certain groups makes them unappealing.

In Models 1-6, the coefficient of determination is high, indicating that these models for hydrofluorocarbons and perfluorocarbons describe the data well. For terminal carbon groups in all of the models, the coefficient decreases as the number of carbon-fluorine bonds decreases. This is also true for the inner carbon groups. The base values trend indicates that placing more fluorine atoms on a carbon results in a nonlinear increase in infrared absorption intensity and 
radiative efficiency. Of all the models, the Model 1 and 2, presented in Table 1, are the simplest and have the desirable quality of all positive base values, besides being accurate. Model 2, with no intercept, no interaction terms and only base values for one-carbon units would be our method of choice for estimating the infrared intensities of hydrofluoro- and perfluorocarbons.

\section{Hydrofluoroether and Perfluoroether Models}

The second class of molecules we modeled are the hydrofluoroethers and perfluoroethers. We used $a b$ initio quantum chemical methods to calculate the harmonic frequencies and vibrational intensities of IR absorption for all combinations of two carbon, three carbon, and four carbon ethers containing one fluorine atom through saturation with multiple fluorine atoms. From this data, the regressions in Table 2 were generated.

Models 7 and 8 are used in a similar manner to models 1 and 2. However, these molecules include groups that contain oxygen atoms. In Models 7 and 8, each one-carbon group is unaffected by the presence of neighboring groups. In the ether molecules, if a carbon group is next to an oxygen, that group is only counted once as a group with an oxygen. This means that a molecule such as $\mathrm{CF}_{3} \mathrm{OCFHCFHCF}_{3}$ contains the four distinct groups $\mathrm{CF}_{3} \mathrm{O}, \mathrm{CFHO}, \mathrm{CFH}$, and $\mathrm{CF}_{3}$. That is, the intensity in the atmospheric IRW would be predicted in the following way:

\section{Model 7}

Intensity in IRW $=132+838 \mathrm{CF}_{3}+453 \mathrm{CF}_{2} \mathrm{H}+213 \mathrm{CFH}_{2}+129 \mathrm{CH}_{3}+301 \mathrm{CF}_{2}+75.7 \mathrm{CFH}+$

$$
\begin{aligned}
& 15.1 \mathrm{CH}_{2}+1310 \mathrm{CF}_{3} \mathrm{O}+752 \mathrm{CF}_{2} \mathrm{HO}+319 \mathrm{CFH}_{2} \mathrm{O}+617 \mathrm{CF}_{2} \mathrm{O}+251 \mathrm{CFHO} \\
& =132+838(1)+453(0)+213(0)+129(0)+301(0)+75.7(1)+15.1(0) \\
& +1310(1)+752(0)+319(0)+617(0)+251(1) \\
& =2606.7 \mathrm{~km} \mathrm{~mol}^{-1}
\end{aligned}
$$




\section{Model 8}

Intensity in IRW $=904 \mathrm{CF}_{3}+519 \mathrm{CF}_{2} \mathrm{H}+279 \mathrm{CFH}_{2}+195 \mathrm{CH}_{3}+301 \mathrm{CF}_{2}+75.7 \mathrm{CFH}+15.1$

$$
\mathrm{CH}_{2}+1376 \mathrm{CF}_{3} \mathrm{O}+818 \mathrm{CF}_{2} \mathrm{HO}+385 \mathrm{CFH}_{2} \mathrm{O}+65.9 \mathrm{CH}_{3} \mathrm{O}+617 \mathrm{CF}_{2} \mathrm{O}+251
$$

\section{CFHO}

$$
=904(1)+519(0)+279(0)+195(0)+301(0)+75.7(1)+15.1(0)+1376(1)
$$

$+818(0)+385(0)+65.9(0)+617(0)+251(1)$

$=2606.7 \mathrm{~km} \mathrm{~mol}^{-1}$

In Model 7, the $\mathrm{CH}_{2} \mathrm{O}$ group and the $\mathrm{CH}_{3} \mathrm{O}$ were highly correlated with other predictor variables and were automatically removed from the regression equation. In Model 8, only the $\mathrm{CH}_{2} \mathrm{O}$ group had high correlation with other predictor variables and was not included in the regression equation. In some extreme cases both Model 7 and Model 8 may predict the same intensities for two molecules, which are constitutional isomers with similar groups. For example, both Model 7 and Model 8 would predict the same intensities for $\mathrm{CF}_{3} \mathrm{CF}_{2} \mathrm{OCH}_{2} \mathrm{CH}_{3}$ and $\mathrm{CH}_{3} \mathrm{CF}_{2} \mathrm{OCH}_{2} \mathrm{CF}_{3}$ even though these molecules have slightly different absorption intensities and radiative efficiencies.

Models 9 and 10, included in (supporting information) are used for fluoroethers in a similar manner as Models 3 and 4 for fluorocarbons and are the most sophisticated models. They also contain oxygen groups, which are used in the same way as in Models 7 and 8, i.e. if a group is next to an oxygen atom then that group is only counted along with the oxygen. This model did not contain the possible interactions with terminal oxygenated groups since it was determined from early models that interaction terms in general had fairly high correlations with other predictor variables and so not all interaction terms may be necessary. While the interaction terms do contribute to improving the additive model, it was decided that only some of the interaction 
terms needed to be included. In Model 10, when the regression was run the groups $\mathrm{CH}_{2} \mathrm{O}$, $\mathrm{CH}_{3} / \mathrm{CF}_{2}, \mathrm{CH}_{3} / \mathrm{CFH}, \mathrm{CH}_{3} / \mathrm{CH}_{2}, \mathrm{CF}_{2} \mathrm{O} / \mathrm{CH}_{2}, \mathrm{CFHO} / \mathrm{CH}_{2}, \mathrm{CF}_{3} / \mathrm{CH}_{2}, \mathrm{CF}_{2} \mathrm{H} / \mathrm{CH}_{2}, \mathrm{CFH}_{2} / \mathrm{CH}_{2}$, $\mathrm{CH}_{2} \mathrm{O} / \mathrm{CH}_{3}, \mathrm{CH}_{2} \mathrm{O} / \mathrm{CF}_{2}, \mathrm{CH}_{2} \mathrm{O} / \mathrm{CFH}$, and $\mathrm{CH}_{2} \mathrm{O} / \mathrm{CH}_{2}$ were highly correlated with other predictor variables and were removed from the regression equation. For Model 9, the $\mathrm{CH}_{3} \mathrm{O}$ group was highly correlated with other predictor variables in addition to the highly correlated terms from Model 10 and so all of these terms were removed from the regression. These two models also have the undesirable property of having negative interaction terms between one-carbon groups.

Model 11 is used in the same way as Model 7 except the constant term is multiplied by the number of carbons the molecule contains. In certain cases, Model 11 does predict the same intensities for two different molecules that contain the same groups. Models 7, 8, and 11 predict the same fitted intensities in the IRW for each molecule. Similarly, Model 12 is used like Model 9 with the constant term multiplied by the number of carbons in the molecule. Models 9,10 , and 12 give the same predicted intensities in the IRW for a molecule. All of the models have symmetric, bell shaped histograms that are centered on zero and have similar ranges for the residuals presented in the supporting information. The histograms in addition to the $\mathrm{R}^{2}$ values indicate that Models 7-12 predict the intensities well for the hydrofluoro- and the perfluoroethers. The nearest-neighbor models do have a slightly lower average residual and do not predict the same intensities for different molecules, but are more complicated than the additive models. In addition, in Models 9-12 there are some negative coefficients. This is once again due to the effects of multicollinearity, since there are some predictor variables that are highly correlated with other predictor variables. The negative coefficients do not necessarily mean that the group or interaction does not positively contribute to the absorption intensity in the IRW, it means that in order to counteract the overestimation of effects of other dependent groups 
some of the coefficients must be negative. In all of these models, the coefficients increase as more fluorines are added to a terminal or inner carbon. This is in agreement with previous studies, ${ }^{8,9}$ which show that an increase in carbon-fluorine bonds results in a nonlinear increase in intensity for absorption within the IRW, and also with the observations of Blowers et al. ${ }^{15,16}$ Also, the coefficients for the groups containing oxygen are higher than the coefficients of the equivalent non-oxygenated groups. This agrees with observations made previously that fluorinated carbons situated next to an oxygen result in a larger absorption in the IRW or a larger radiative efficiency. ${ }^{9,12}$ The additive models, especially Model 8, are most appealing for being simplest and having all positive base values and therefore will be favored by us for estimating the intensities of hydrofluoroethers and perfluoroethers.

\section{Conclusions}

Several models were created to assess the vibrational absorption intensity of a molecule's absorption within the IRW. The additive models (models 1 and 2 for the hydrofluorocarbons and 7 and 8 for the perfluorocarbons) gave good agreement with experiment while retaining positive coefficients. These are the models that we would recommend. The additive models $(1,2,7$ and 8) account for the contributions, 'base values', from different one-carbon groups while the nearest- neighbor models $(5,6,11$, and 12$)$ take into consideration the effects of interactions for groups that are next to each other. The interaction models $(3,4,9$, and 10) for hydrofluorocarbons and perfluorocarbons take into account all possible interactions between groups. The constant models and carbon constant models include a term that can account for residual intensities. The carbon constant and no-constant models include one term that was removed from the respective constant model due to a high correlation. The coefficients of the 
models for both fluorinated ethers and fluorinated hydrocarbons indicate that increasing the number of fluorines on a carbon results in a nonlinear increase in the molecule's absorption of radiation within the IRW. The ether models' base values show that fluorinated carbons next to an oxygen atom contribute more to the IRW absorption intensity than their respective nonfluorinated counterparts do. The nearest neighbor models and interaction models include unphysical negative coefficients or base values; these negative coefficients are the result of fairly high correlations between predictor variables. All the models have high $\mathrm{R}^{2}$ values indicating that they explain the data well. However, some of the models do predict the same intensities for different molecules. Overall, these models offer several simple ways to estimate the relative infrared absorption intensities and hence radiative efficiencies of fluorcarbons and fluoroethers.

Finally, we note that use of these models together with climate models would necessitate that the climate model treat trace species that absorb radiation within the IRW separately and differently relative to more abundant atmospheric molecules (such as $\mathrm{CO}_{2}, \mathrm{H}_{2} \mathrm{O}, \mathrm{N}_{2} \mathrm{O}$, and $\mathrm{CH}_{4}$ ). This would seem to be prudent since within the IRW there is, by definition, an over abundance of available photons to be absorbed, and that trace species will not be able to absorb and process all the photons of a given wavelength within the IRW.

\section{Acknowledgements}

This paper is dedicated to Professor Boris Galabov on the occasion of his 70th birthday, who has made seminal contributions to the study of IR intensities. SIK gratefully acknowledges an Undergraduate Student Research Program (USRP) summer fellowship at the NASA Ames

Research Center. PPB gratefully acknowledges a NASA Postdoctoral Program Fellowship award. Helpful conversations with Dr. Jeff Cuzzi are gratefully acknowledged. 
Tables

Table 1. Least Squares Regression Models for Hydrofluorocarbons and Perfluorocarbons. Averaged absolute residuals are expressed in $\mathrm{km} \mathrm{mol}^{-1}$.

\begin{tabular}{|c|c|c|c|c|c|c|c|}
\hline Regression Model & $\begin{array}{l}\text { Constant } \\
\text { terms? }\end{array}$ & $\begin{array}{l}\text { Quadratic } \\
\text { Terms? }\end{array}$ & $\begin{array}{l}\text { Data } \\
\text { Excluded }\end{array}$ & $\begin{array}{l}\mathbf{R}^{2} \\
\%\end{array}$ & Outliers & $\begin{array}{l}\text { Averaged } \\
\text { Absolute } \\
\text { Residuals }\end{array}$ & $\begin{array}{l}\text { Largest } \\
\text { Residual } \\
\text { km mol }\end{array}$ \\
\hline $\begin{array}{l}\text { Model } 1 \\
\text { Additive- With Intercept: } \\
\text { Intensity in IRW }=86.6+ \\
704 \mathrm{CF}_{3}+303 \mathrm{CF}_{2} \mathrm{H}+ \\
77.2 \mathrm{CFH}_{2}+289 \mathrm{CF}_{2}+ \\
75.6 \mathrm{CFH}+14.8 \mathrm{CH}_{2}\end{array}$ & Yes & no & $\begin{array}{l}\text { All one- } \\
\text { carbon } \\
\text { molecules }\end{array}$ & 99.3 & $\mathrm{CF}_{3} \mathrm{CH}_{2} \mathrm{CH}_{2} \mathrm{CF}_{3}$ & 28.3 & $\begin{array}{l}138.4 \text { for } \\
\mathrm{CF}_{3} \mathrm{CH}_{2} \mathrm{CH}_{2} \mathrm{CF}_{3}\end{array}$ \\
\hline $\begin{array}{l}\text { Model } 2 \\
\text { Additive-No Intercept: } \\
\text { Intensity in IRW }=748 \\
\mathrm{CF}_{3}+346 \mathrm{CF}_{2} \mathrm{H}+121 \\
\mathrm{CFH}_{2}+43.3 \mathrm{CH}_{3}+289 \\
\mathrm{CF}_{2}+75.6 \mathrm{CFH}+14.8 \\
\mathrm{CH}_{2}\end{array}$ & No & no & $\begin{array}{l}\text { All one- } \\
\text { carbon } \\
\text { molecules }\end{array}$ & 99.3 & $\mathrm{CF}_{3} \mathrm{CH}_{2} \mathrm{CH}_{2} \mathrm{CF}_{3}$ & 28.3 & $\begin{array}{l}138.4 \text { for } \\
\mathrm{CF}_{3} \mathrm{CH}_{2} \mathrm{CH}_{2} \mathrm{CF}_{3}\end{array}$ \\
\hline
\end{tabular}

Figure 1. Histograms of Residuals for Models 1 and 2. (1) Histogram of residuals for Model

1. (2) Histogram of residuals for Model 2. 
(1)

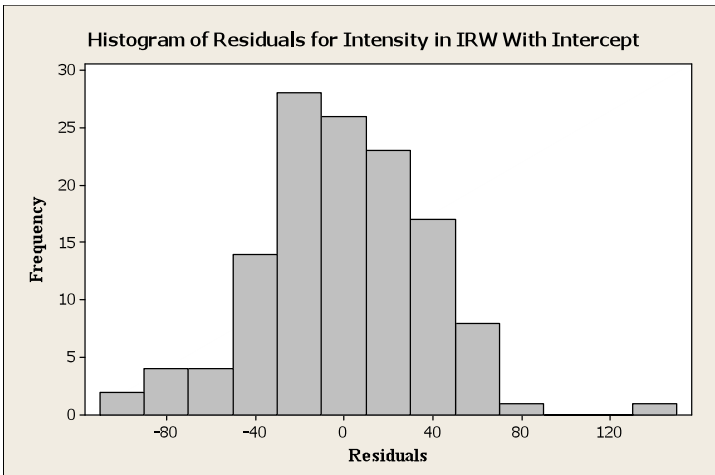

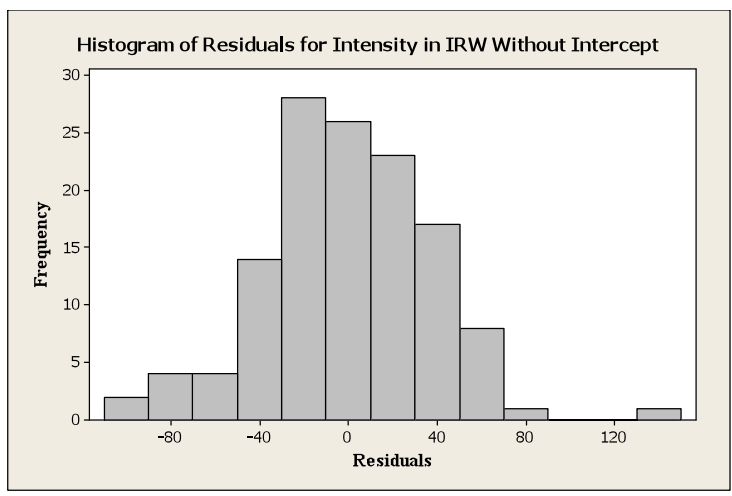

(2)

Table 2. Least Squares Regession Models for Hydrofluoroethers and Perfluoroethers. Averaged absolute residuals are expressed in $\mathrm{km} \mathrm{mol}^{-1}$.

\begin{tabular}{|c|c|c|c|c|c|c|}
\hline Regression Model & $\begin{array}{l}\text { Constant } \\
\text { term? }\end{array}$ & $\begin{array}{l}\text { Quadratic } \\
\text { Terms? }\end{array}$ & $\begin{array}{l}\mathrm{R}^{2} \\
\%\end{array}$ & Outliers & $\begin{array}{l}\text { Averaged } \\
\text { Absolute } \\
\text { Value of } \\
\text { Residuals }\end{array}$ & $\begin{array}{l}\text { Largest } \\
\text { Residual } \\
\text { km mol}^{-1}\end{array}$ \\
\hline $\begin{array}{l}\text { Model } 7 \\
\text { Additive With Constant: } \\
\text { Intensity in IRW }=132+838 \mathrm{CF}_{3}+453 \\
\mathrm{CF}_{2} \mathrm{H}+213 \mathrm{CFH}_{2}+129 \mathrm{CH}_{3}+301 \mathrm{CF}_{2} \\
\qquad+75.7 \mathrm{CFH}+15.1 \mathrm{CH}_{2}+1310 \\
\mathrm{CF}_{3} \mathrm{O}+752 \mathrm{CF}_{2} \mathrm{HO}+319 \mathrm{CFH}_{2} \mathrm{O} \\
\qquad+617 \mathrm{CF}_{2} \mathrm{O}+251 \mathrm{CFHO}\end{array}$ & Yes & no & 99.7 & $\begin{array}{l}\text { Possible } \\
\text { Outlier: } \\
\mathrm{CF}_{2} \mathrm{HOCF}_{2} \mathrm{CF}_{2} \\
\mathrm{CFH}_{2}\end{array}$ & 27.2 & $\begin{array}{l}113.3 \text { for } \\
\mathrm{CF}_{2} \mathrm{HOCF}_{2} \mathrm{CF}_{2} \\
\mathrm{CFH}_{2}\end{array}$ \\
\hline $\begin{array}{l}\text { Model } 8 \\
\text { Additive-No constant } \\
\text { Intensity in IRW }=904 \mathrm{CF}_{3}+519 \mathrm{CF}_{2} \mathrm{H}+ \\
279 \mathrm{CFH}_{2}+195 \mathrm{CH}_{3}+301 \mathrm{CF}_{2}+75.7 \mathrm{CFH} \\
+15.1 \mathrm{CH}_{2}+1376 \mathrm{CF}_{3} \mathrm{O}+818 \mathrm{CF}_{2} \mathrm{HO}+ \\
385 \mathrm{CFH}_{2} \mathrm{O}+65.9 \mathrm{CH}_{3} \mathrm{O}+617 \mathrm{CF}_{2} \mathrm{O}+251 \\
\mathrm{CFHO}\end{array}$ & No & no & 99.7 & $\begin{array}{l}\text { Possible: } \\
\mathrm{CF}_{2} \mathrm{HOCF}_{2} \mathrm{CF}_{2} \\
\mathrm{CFH}_{2}\end{array}$ & 27.2 & $\begin{array}{l}113.3 \text { for } \\
\mathrm{CF}_{2} \mathrm{HOCF}_{2} \mathrm{CF}_{2} \\
\mathrm{CFH}_{2}\end{array}$ \\
\hline
\end{tabular}


Figure 2. Histograms of Residuals for Hydrofluoroether and Perfluoroether Models. (7)

Histogram of residuals for Model 7. (8) Histogram of residuals for Model 8.

(7)

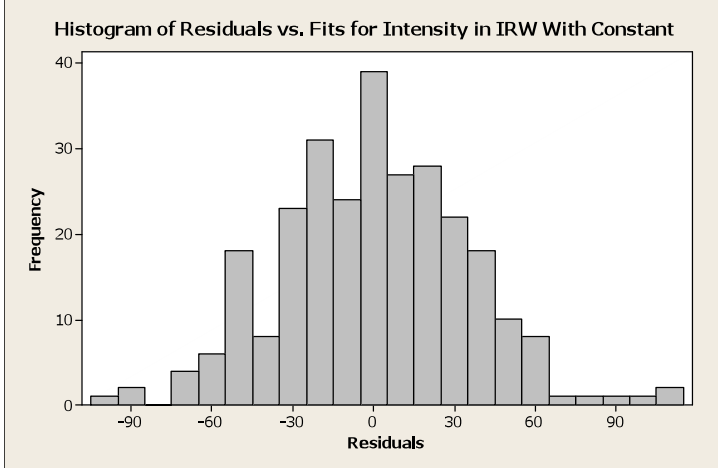

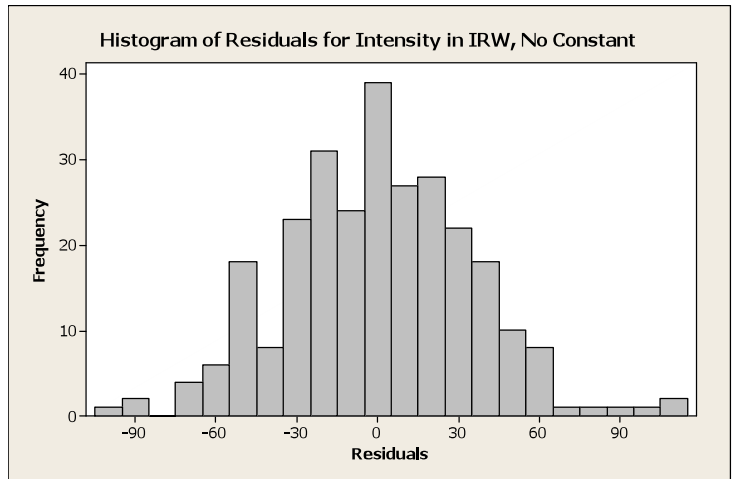

References

1 J. T. Houghton, B. A. Callander, and S. K. Varney, Climate Change: The Intergovernmental Panel on Climate Change Scientific Assessment. (Cambridge University Press, Cambridge, UK, 1990). N. D. Smith, edited by E.P.A. (EPA, Research Triangle Park, N.C., 1992).

3 S. Devotta, S. Gopichand, and V. R. Pendyala, Assesment of HFCs, fluorinated ethers and amine as alternative to CFC12, Int. J. Refrig. 16, 84 (1993).

$4 \quad$ I. H. Rowlands, Environment 35, 25 (1993).

5 S. Hassoun, T. McBride, and D. R. Russell, Developement of perfluorocarbon tracer technology for underground leak location, J. Environ. Monit. 2, 432 (2000).

6 R. K. Spence, Perfluorocarbons in the twenty-first century: clinical applications as transfusion alternatives, Artif. Cells Blood Substit. Immobil. Biotechnol. 23 (3), 367 (1995).

7 S. Solomon, D. Qin, M. Manning, Z. Chen, M. Marquis, K. B. Averyt, M. Tignor, and H. L. Miller, Climate Change 2007: The Physical Science Basis. Contribution of Working Group I to the Fourth Assessment Report of the Intergovernmental Panel on Climate Change. (Cambridge University Press, Cambridge, UK, 2007).

8 P. P. Bera, J. S. Francisco, and T. J. Lee, Identifying the molecular origin of global warming, J. Phys. Chem. A 113, 12694 (2009).

9 P. P. Bera, J. S. Francisco, and T. J. Lee, Design strategies to minimize radiative efficiencies of global warming molecules, Proc. Natl. Acad. Sci. 107, 9049 (2010). 
D. L. Cooper, T. P. Cunningham, N. L. Allan, and A. McCulloch, Potential CFC Replacements, Atmos. Environ. 27A, 117 (1993).

W. T. Tsai, Environmental risk assesment of hydrofluoroethers, J. Hazard. Mat. A119, 69 (2005).

C. J. Young, M. D. Hurley, T. J. Wallington, and S. A. Mabury, Molecular structure and radiative efficiency of fluorinated ethers: a structure activity relationship, J. Geophys. Res. 113, D24301 (2008).

I. Bravo, G. Marston, D. R. Nutt, and K. P. Shine, Radiative efficiencies and global warming potentials using theoretically determined absorption cross sections for several HFEs and HFPEs, J. Quant. Spectrosc. Radiat. Trans. 112, 1967 (2011).

P. P. Bera, L. Horny, and H. F. Schaefer, Cyclic perfluorocarbon radicals and anions having high global warming potentials (GWPs): structures, electron affinities, and vibrational frequencies, J. Am. Chem. Soc. 126 (6692-6702) (2004).

P. Blowers, D. M. Moline, K. F. Tetrault, R. R. Wheeler, and K. F. Tetrault, Prediction of radiative forcing values for hydrofluoroethers using density functional theory methods, J. Geophys. Res. 112, D15108 (2007).

P. Blowers, D. M. Moline, K. F. Tetrault, R. R. Wheeler, and S. L. Tuchawena, Global warming potentials of hydrofluoroethers, Environ. Sci. Technol. 42, 1301 (2008).

I. Bravo, A. Aranda, M. D. Hurley, G. Marston, D. R. Nutt, K. P. Shine, K. Smith, and T. J. Wallington, Infrared absorption spectra, radiative efficiencies, and global warming potential of perfluorocarbon: comparison between experiment and theory, J. Geophys. Res. 115, D24317 (2010).

E. J. Highwood and K. P. Shine, Radiative forcing and global warming potential of 11 halogenated molecules, J. Quant. Spectrosc. Radiat. Transf. 66, 169 (2000).

S. W. Benson and J. H. Buss, Additivity rules for the estimation of molecular properties and thermodynamic properties, J. Chem. Phys. 29, 546 (1958).

T. J. Wallington, M. P. S. Andersen, and O. J. Nielsen, Relative integrated IR absorption in the atmospheric window is not the same as replative radiative efficiency, Proc. Natl. Acad. Sci. 107, E178 (2010).

P. P. Bera, J. S. Francisco, and T. J. Lee, Reply to Wallington et al.: Differences in electronic structure of global warming molecules lead to different molecular properties, Proc. Natl. Acad. Sci. 107, E180 (2010).

S. Pinnock, M. D. Hurley, K. P. Shine, T. J. Wallington, and T. J. Smyth, Radiative forcing of climate by HFCs and PFCs, J. Geophys. Res. 100, 23227 (1995).

K. P. Shine, On the cause of relative greenhouse strenght of gases such as the halocarbons, J. Atmos. Sci. 48, 1513 (1991).

T. H. Dunning, Gaussian basis functions for use in molecular calculations. I. contraction of (9s5p) atomic basis sets for the first-row atoms, J. Chem. Phys. 53, 2823 (1970).

T. H. Dunning, Gaussian basis functions for use in molecular calculations. IV. the representation of polarization functions for the first row atoms and hydrogen, J. Chem. Phys. 55, 3958 (1971).

S. Huzinaga, Gaussian type functions for polyatomic systems, J. Chem. Phys. 42, 1293 (1965).

S. Parthiban and T. J. Lee, Unpublished work, (1999). 
T. J. Lee, Application of Ab Initio Quantum Chemistry to Global Warming Atmospheric Chemistry, Mulliken Lecture, Center for Computational Quantum Chemistry, University of Georgia, Athens, Georgia, 26 October, (1999). Y. Shao, L. F. Molnar, Y. Jung, J. Kussmann, C. Ochsenfeld, S. T. Brown, A. T. B. Gilbert, L. V. Slipchenko, S. V. Levchenko, D. P. O'Neill, R. A. DiStasio, R. C. Lochan, T. Wang, G. J. O. Beran, N. A. Besley, J. M. Herbert, C. Y. Lin, T. Van Voorhis, S. H. Chien, A. Sodt, R. P. Steele, V. A. Rassolov, P. E. Maslen, P. P. Korambath, R. D. Adamson, B. Austin, J. Baker, E. F. C. Byrd, H. Dachsel, R. J. Doerksen, A. Dreuw, B. D. Dunietz, A. D. Dutoi, T. R. Furlani, S. R. Gwaltney, A. Heyden, S. Hirata, C. P. Hsu, G. Kedziora, R. Z. Khalliulin, P. Klunzinger, A. M. Lee, M. S. Lee, W. Liang, I. Lotan, N. Nair, B. Peters, E. I. Proynov, P. A. Pieniazek, Y. M. Rhee, J. Ritchie, E. Rosta, C. D. Sherrill, A. C. Simmonett, J. E. Subotnik, H. L. Woodcock, W. Zhang, A. T. Bell, A. K. Chakraborty, D. M. Chipman, F. J. Keil, A. Warshel, W. J. Hehre, H. F. Schaefer, J. Kong, A. I. Krylov, P. M. W. Gill, and M. Head-Gordon, Advances in methods and algorithms in a modern quantum chemistry program package, Phys. Chem. Chem. Phys. 8 (27), 3172 (2006). M. Gussoni, G. Zerbi, and W. Person, Presentation of molecular parameter values for infrared and raman intensity measurements, Pure Appl. Chem. 60, 1385 (1988). B. Galabov, Y. Yamaguchi, R. B. Remington, and H. F. Schaefer, High level ab initio quantum mechanical predictions of infrared intensities J. Phys. Chem. A 106, 819 (2002).

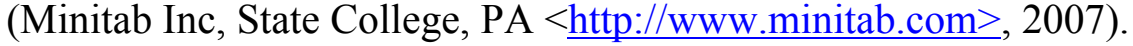

S. Weisberg, Applied Linear Regression, 3rd ed. (John Wiley and Sons Inc, Hoboken, NJ, 2005). 